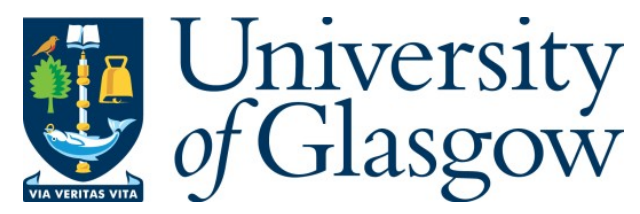

Lawson, L. and Kearns, A. (2020) Foodbanks as paradoxes of policy and society. Voluntary Sector Review. (Early Online Publication)

(doi: 10.1332/204080520X15926573026085)

This is the Author Accepted Manuscript.

There may be differences between this version and the published version. You are advised to consult the publisher's version if you wish to cite from it.

https://eprints.gla.ac.uk/218807/

Deposited on: 23 June 2020

Enlighten - Research publications by members of the University of Glasgow http://eprints.gla.ac.uk 


\title{
Foodbanks as Paradoxes of Policy and Society
}

\section{Louise Lawson and Ade Kearns}

\begin{abstract}
We explore the informal relationship between foodbanks and the state during the period of welfare reform, using evidence from a qualitative study of foodbank users in Glasgow, UK. We examine how changes in the welfare state are reflected in what foodbanks do, how they operate, and the expectations and experiences of foodbank users. Our research framework contains three paradoxes: people are knowingly failed by recent welfare reforms and subsequently referred by state and third sector agencies to charitable foodbanks; the voluntary sector cannot adequately support vulnerable people who have needs that are more than food-related, due to state cutbacks; and, community food initiatives play a role in helping people in severe financial hardship, but are fundamentally different and not a replacement for foodbanks. We show that in the case of foodbanks, the voluntary sectorstate relationship is more profound and consequential for foodbanks and citizens than any formal arrangements would suggest.
\end{abstract}

\section{Key words}

Austerity, Poverty, Voluntary-sector, Welfare-reform 


\section{Introduction}

Foodbanks and other forms of charitable provision are de facto becoming part of the UK welfare landscape, something government and others are trying to counter (Garthwaite, 2016; Lambie-Mumford, 2018). Foodbanks became increasingly prevalent in the UK following the financial crisis in 2008 , and after austerity measures were introduced by the government in 2010. People using foodbanks are in severe financial hardship. The characteristics of foodbank users include unemployment, experiencing benefit problems, being lone parents, and people with disabilities and health conditions. The main issues that cause working people to be referred to foodbanks are low wages, insecure work, high living costs and problems accessing working benefits (Trussell Trust, 2017).

Most foodbanks in the UK are coordinated by The Trussell Trust, a Christian-based charity that had just two foodbanks in 2004, but now supports a vast network of foodbanks throughout the UK. In the financial year 2018-19 it gave out 1,583,668 three-day emergency food supplies, a 19\% increase on the previous year (Trussell Trust, 2019). There are currently more than 1,200 food bank centres in the Trussell Trust's network across the UK. The Trussell Trust network accounts for roughly two-thirds of all emergency food banks The Independent Food Aid Network shows there are at least an additional 805 independent food banks (IFAN, 2019). In most cases, frontline staff from public agencies (e.g. schools, social work employment centres) can refer people to foodbanks if their situation warrants emergency food provision; a voucher is issued and redeemed for a three-day emergency food parcel. However, many independent foodbanks do not require a referral from a thirdparty organisation in order to receive a food parcel. Foodbanks cannot generally be used on a regular ongoing basis, but the situation varies depending on the type of foodbank. There are more rules and restrictions on Trussell Trust foodbanks compared to independent ones that do not always require a referral and can offer a wider range of supplies.

Foodbanks have received a lot of political, media, and academic interest. A detailed ethnographic account is available detailing how foodbanks work, including an inside account of the feelings and experiences of users and volunteers (see Garthwaite, 2016a, 2016b). Other scholarly articles and commentaries have examined poverty issues and foodbank use from different perspectives, including the views of volunteers and foodbanks recipients, with 
a view to furthering the evidence base and research agenda in this field (Lambie-Mumford, 2017; Perry et al, 2014).

In this article we explore foodbanks as paradoxes of policy and society. In relation to this we have identified three paradoxes as a way of framing the research. These focus on welfare reform as creating the need for foodbanks, the voluntary sector and state cutbacks, and the role of community food initiatives in the current policy climate. We present qualitative evidence from 23 foodbank participants to compare their expectations and experiences of foodbank use, which provides further evidence of a paradox. The conclusion brings together foodbank participants' expectations and experiences within the context of the framework.

\section{Three Foodbank Paradoxes}

In the current period, foodbanks represent an anomaly that does not fit the previous models of voluntary sector-state relationship. The relationship between the voluntary sector and the state in the UK has been seen in one of a number of ways, depending on the era concerned (Lewis, 1999). The voluntary sector can do things that the state does not, the so-called 'separate spheres' model of the late nineteenth and early twentieth centuries; by the midtwentieth century, the relationship was described as an 'extension ladder', with the voluntary sector complementing the welfare state; in the 1980 s and 90 s, the relationship changed again to a contractual one, with the voluntary sector now an 'alternative provider' for welfare services no longer provided directly by the state. After sectoral reviews (Home Office, 1990; Deakin, 1996), the relationship shifted to one of partnership, with the voluntary sector accountable for its performance, but able to act independently and help formulate and criticise policy (Alcock, 2010; Home Office, 1998). These models of the voluntary sectorstate relationship vary in their view of key issues such as which party has primary responsibility for those in need, and whether or not voluntary action is of value for its contribution to society and democracy, or only valuable to the extent that it is professional and accountable.

Foodbanks, however, appear to be an anomaly, in that they do not serve a narrowly defined and separate social group that is outwith state support, nor do they exist to complement or extend welfare provision. Rather, they seem to provide goods and services that the state is supposed to ensure for its citizens, even though foodbanks are not in any formal relationship with the state. Prima facie evidence suggests that the rapid rise of foodbank use from 2011 , 
and persistent high rates of usage across the country since, are cumulative outcomes of the many changes to the welfare system over this period (Loopstra et al, 2018; Trussell Trust 2018). Both sides - government and third sector - declare they would rather foodbanks did not exist and insist that foodbanks are not an integral part of the welfare state, and yet neither side expects foodbanks to disappear anytime soon; indeed there seems to be an implicit assumption on the part of the state and voluntary sector that foodbanks will continue to serve the poor. Three paradoxes illustrate the opaque and complicated connection between foodbanks, the state, and the voluntary sector.

\section{Paradox 1: Welfare Reform and Foodbanks}

A clear connection to the state has been identified in that foodbank use has been linked to UK welfare reform, which has led to people dealing with increased hardship and destitution, and the consequences of sanctions and appeals (Dowler and Lambie-Mumford, 2015).

Policies of austerity and welfare reform report the largest cuts in public finance ever seen and some of the most extensive welfare reforms since the introduction of the welfare state in the 1940s. The paradox we go on to describe is that people who have been let down by the welfare system due to punitive welfare reforms, are assessed and referred by frontline staff in public and third sector agencies to foodbanks which are predominantly charitable enterprises, in order to meet a basic state responsibility.

A series of reforms were introduced with the Conservative-Liberal Democrat coalition Government's Welfare Reform Act 2012 in order to cut the welfare budget. It affected poorest people the hardest (Wright, 2016; Patrick, 2014), including a cap on the total amount of benefits any household with children could receive, the 'Bedroom tax'11, extended waiting times for Jobseekers Allowance (JSA) or Employment Support Allowance (ESA) ${ }^{2}$, and the 'two child limit' ${ }^{3}$ restricting eligibility to some social security benefits. Furthermore, the

\footnotetext{
${ }^{1}$ The under-occupancy penalty (or spare room subsidy) results from a reform contained in the Welfare Reform Act 2012 whereby tenants living in social housing (local authority or housing association) with rooms deemed "spare" face a reduction in Housing Benefit, resulting in them being having to fund this reduction from their incomes or to face rent arrears and potential eviction by their landlord.

2 Jobseeker's Allowance (JSA) is a benefit for people while they look for employment. Employment and Support Allowance (ESA) is a benefit for people with a disability or health condition that affects how much they can work.

${ }^{3}$ The two-child limit applies to children born after 6 April 2017 meaning that in families where there are already two or more children, the child element in Universal Credit and tax credits - - is restricted to the first two children.
} 
abolition of the discretionary social fund - i.e., crisis loans, community care grants and budgeting loans - represents the removal of a vital safety net. Universal Credit ${ }^{4}$, replacing a range of in and out-of-work benefits, has been criticised for flaws in its inception, design and delivery (Wright, 2016).

In parallel with greater conditionality requirements and consequent sanctions, there is evidence that the UK experienced a dramatic rise in foodbank usage (Loopstra et al, 2018). The Welfare Reform Act increased the severity of the sanctions that could be applied to benefit claimants not meeting certain conditions, e.g. failing to actively seek work, participate in training and employment schemes, or attend interviews (Adler, 2016: 199). When people fail to meet the criteria, sanctioning occurs, which means claimants have their benefit payments stopped, with immediate effect, for a period of time (minimum 4 weeks) depending on the severity of the breach (Department for Work and Pensions, 2013). Furthermore, the sanctions regime has driven real hardship, resulting in a substantial or complete loss of income for those who tend to lack other means of support (Adler 2016; Fletcher and Wright, 2018). There are also concerns about the fairness of the practices. Sanctions may actually reduce re-employment among particular vulnerable groups (Reeves and Loopstra, 2017), with those suffering most being people who are disadvantaged to start with, particularly those with complex needs including lone parents, disabled people, people with mental health issues, homeless people, and some minority ethnic groups (Adler, 2016).

There is now a deep mistrust of the welfare system, which is putting more pressure on people attempting to claim their entitlements (Garthwaite, 2011). A Parliamentary Inquiry into Personal Independence Payment (PIP) ${ }^{5}$ and ESA received distressing accounts from thousands of people navigating the claims process, alongside managing their disability and mental health issues, and drew attention to the stress associated with challenging a decision (House of Commons, 2018). Examples of people's experiences of appeals include being hospitalised after assessments, increasing their medication and attempting suicide (Rethink, 2017; Warren et al, 2014). Thus, many people feel unable to claim the social rights to which they are entitled, and a significant amount of work goes into claiming, defending and fighting

\footnotetext{
${ }^{4}$ Universal Credit (UC) was introduced in 2013 in an attempt to simplify the welfare system by 'rolling' six means-tested benefits and tax credits into a single monthly payment - but has been increasingly criticised in recent years.

${ }^{5}$ Personal Independence Payment (PIP) is a benefit for extra help for people with an illness, disability or mental health condition
} 
for such rights (Edmiston, 2017). Opponents of conditional approaches see them as punitive, disciplinary and iniquitous, 'punishing the poor' by holding them to standards or conduct not required of more advantaged groups (Adler, 2016).

The welfare state is meant to protect its citizens: through a universal offer of public services and social security, the state should ensure that everyone achieves a good minimum standard of living (McNeil et al, 2019). This should include enough income to live, and access to basic goods and services such as housing, food, fuel and healthcare. However, the current system means people do not get the social protections they deserve, endure hardship and destitution, and there is an increasingly patchy safety net for which people have no choice but to turn to foodbanks.

\section{Paradox 2: Voluntary Sector Cuts and Support}

State funding to the voluntary sector was significantly cut during the period of austerity and many services were reduced or forced to close at a time when there has been a greater need for them, particularly by foodbank users who have greater support needs. Paradoxically, at a time when there is the need for more [voluntary] support for people experiencing poverty, austerity cuts to public spending are also shown to have uneven impacts, resulting in larger reductions in local authority spending in many of the poorest cities in the UK where there is greatest need (Hood and Waters, 2017).

Consistent evidence and testimony indicate that disadvantaged and marginalised groups including women, children, disabled people, older people, ethnic minorities, migrants and refugees are disproportionately affected by austerity measures; the same groups most likely to need to access foodbanks, and where support for vital services has been cut. Research on the impact of welfare reform from the perspective of third sector organisations has found significant gaps in the provision of support services, including advocacy and representation, one-to-one support, community-based support, and job seeker support (Scottish Council for Voluntary Organisations, 2014). People experiencing mental distress are a key group of people who have been hit hardest, for instance in the targeting of disability and ill-health related benefits (Equality and Human Rights Commission, 2018; Mattheys, 2015), yet 
cutbacks have led to the closures of services for these groups including mental health services and provision by third sector organisations (White, 2014; Mattheys, 2015).

Significant effort goes into 'trying to survive' on low income (Patrick 2014; Wright 2012). People on low incomes are highly active in surviving their poverty, managing budgets, negotiating poor transport links to jobs, shops and services and poor housing, all of which can negatively impact upon health (Lister, 2015). However, the cumulative effects of financial hardship and the social stigma that goes alongside it can cause a significant degree of psychological trauma and stress for many, requiring support needs that are beyond financial (Edmiston, 2017).

Typically, support services and groups located within voluntary and community organisations and are best served to their communities. As well as providing public services by contract on behalf of the state, voluntary projects offer grass-roots led responses to local needs, and can also be regarded as an agent of social change through tackling issues on the ground or campaigning for action. With cutbacks, voluntary sector resources have been redirected towards resolving benefit disputes and dealing with sanctions, disrupting voluntary work with service users. Frontline staff in the voluntary sector have had to deal with very emotional issues when there is nowhere else for individuals and families to turn because the appropriate services are no longer available (Webster, 2014; White, 2014). Indeed, foodbanks are not only about providing basic rations, but have also become a listening ear for many. The Trussell Trust describes the visit to a foodbank as "a warm welcome into a safe environment, a listening ear from trained volunteers and a food parcel" (Trussell Trust, 2019), and this the support role of foodbanks has been endorsed by others (e.g. Garthwaite, 2016).

\section{Paradox 3: State Funding for Community Food Initiatives (CFIs)}

Community food initiatives in the UK are different from foodbanks. The main purpose of foodbanks is to respond to personal financial crises and offer basic sustenance until such crises are resolved. Whilst CFIs are often seen as part of the solution for people experiencing poverty, they differ from foodbanks in terms of their philosophical approach, 
ethos, values, and the participation required from users e.g. food growing and cooking, community development, food sustainability. Both foodbanks and CFIs are part of community food aid, but as an emergency response CFIs have limited remit and provision. The paradox is that the state provides funding for many community food initiatives which are mainly viewed as positive enterprises. However, it is the demise of the state that has led to the rise in foodbanks which are predominantly charitable organisations (not state funded) but which state agencies make referrals to, and which have negativity and stigma attached to them, as we go on to illustrate.

Community food initiatives have been championed as a way of meeting the needs of lowincome households for easily accessible good quality food at prices that can be afforded, forming a component of anti-poverty, and social exclusion strategies (Dowler, 2003). Food justice movements build on the notion of the right to food, and there is already a body of critical scholarship advocating for a rights-based approach to solving food poverty in the UK (Dowler and O'Connor 2012, Caraher and Dowler 2014, Dowler and Lambie-Mumford 2015). Advocates of food justice argue that communities should have a central and fundamental role in tackling food injustice "from the ground up". As such, food justice projects often try to promote community food growing, local food systems, and community enterprise or trade networks.

Conversely, foodbanks initially designed as a stop-gap, are predominantly reliant on volunteers, donations and the support of supermarkets and food manufacturers (although local authorities have provided some funding to mainly independent foodbanks). The supermarket chain Asda invested $£ 20$ million in developing foodbank infrastructure (Corporate Asda, 2018) and was reported as 'part of the solution in ending UK hunger' (Trussell Trust, 2018). This appears to be a case of the voluntary sector, with some support from the private sector, addressing an issue that would normally have been considered a state responsibility. The role of charity and religion speaks to a wider issue of who is responsible for providing basic needs such as food, and represents a fragmentation of people's expectations of the state and its responsibilities towards them. Charitable responses can become normalised and serve to legitimise personal generosity as a response to injustice rather than encouraging systemic change. At the same time, in certain sectors of the media, foodbank users are blamed for their poor financial management and faulty behavioural practices (Wells and Caraher, 2014; Garthwaite, 2016), with derogatory 
language used to describe them as freeloaders, undeserving poor and selfish (Purdam, 2015).

There is a middle ground: social supermarkets have emerged to fill a gap for people struggling to meet needs by providing a social safety net. In the short-term, these initiatives provide a degree of choice and dignity to those people who are food insecure, helping them to save money, gain skills and confidence. Such projects have been described a step beyond foodbanks and a help in mitigating the effects of poverty and social vulnerability (Saxena, 2018). 


\section{Research Aims}

We identified three paradoxes relevant to the relationship between foodbanks, the state and the voluntary sector. We aimed to find out how foodbanks users' expectations and experiences relate to these: Our research questions are:

- What are the implications of welfare state reform and treatment for users' expectations and experiences of foodbanks?

- How do foodbanks support the otherwise unmet needs of their users?

- What other forms of support are known, available, and used by participants?

- What role does the voluntary sector, including community food projects, play in supporting foodbank users?

\section{The Research}

The setting for this qualitative research was the city of Glasgow, UK, using the sample from the fourth wave of the GoWell Community and Health and Wellbeing Survey (Egan et.al. 2010). From a sample of approximately 3,500 adult householders (in 2015$), 4.2 \%(n=145)$ had reported using a foodbank in the past year (GoWell, 2016). Members of this group of 145 respondents were invited by letter to participate in the research. Participants opted in to the research by contacting the researcher through a variety of means (including phone or email contact), but the most popular method was by text, following which contact began in order to arrange a time for a face-to-face interview in the participant's home.

There are 23 participants in the sample, who had all used a foodbank on at least one occasion between 2012 and 2017. The sample was evenly divided between adult-only households and families with children or young people. The vast majority of the sample were White Scottish by origin, with a small number of BAME households. Nearly all participants had state benefits as their income source, although two participants were in part-time employment. The self-selective nature of the study is recognised and is partly reflected in the sample characteristics whereby there is under-representation of minority ethnic groups compared with the study sample as a whole. Table 1 summarises participants' characteristics. 
Semi-structured interviews took place in May and June 2017. Interviews focused on: the reasons for foodbank use; the experience of using foodbanks; things happening in participants' lives roundabout the time of their foodbank use and afterwards; and how or if anything in participants' lives had changed since they had used a foodbank. Interviews were audio recorded, professionally transcribed, and analysed by the research team. The data were coded and organised according to the three pre-identified themes; for each theme quotes were selected for illustrative purposes.

Most participants were facing an acute financial crisis or had experienced a reduction in their income, leaving them with little or no money to buy food and other essential items. For most, the immediate income crisis was linked to the operation of the benefits system including waiting for benefit payments, sanctioning, benefit 'mess-ups' and delays. Other participants were simply finding it difficult to manage on a low income, whether they were living on a wage, benefits, home office allowance (if asylum seekers) or a state pension. Mental health issues were commonplace among participants and included stress, depression, attempted suicide, self-harm, anxiety, sleeping problems, worry, panic attacks, agoraphobia, and schizophrenia. Physical and mental health problems were sometimes linked to addiction issues (alcohol and drugs), although mental health problems were also sometimes linked to concerns about employment and incomes. 
Findings: Paradoxes in Foodbank Users' Expectations and Experiences

\section{Expectations: Stigma, Shame, Access}

\section{Negativity, Stigma and Shame}

There was little expectation from participants that the foodbank experience might be a good one. Susan had imagined the foodbanks to be like a soup kitchen, with "everybody lining up". Amanda was just expecting to get tins of food and be rushed in and out:

And that's what it tells you, you're going tae a foodbank... it could be a conveyor belt from what you're telling me... Pick what you need and get oot the door (Amanda)

Previous experiences with state agencies influenced how participants anticipated being treated at foodbanks or how using foodbanks would make them feel. Many participants contrasted their treatment at foodbanks with that of welfare agencies they had encounters with such as the Department for Work and Pensions ${ }^{6}$ and Jobcentre Plus ${ }^{7}$, including undergoing assessments, which were generally regarded as 'harsh', 'cruel' and 'unkind', with a prominence of security officers and a lack of care and respect by staff. Maggie said the social security staff "treat you like dirt. It's 'look at me, I'm working and you're going to foodbanks'”. Kate talked about her lack of control when talking to staff at the benefits agency; the constant fear of your benefits being taken away from you: "they treat you as if you're... rubbish. But you can't argue wi' them or they can take you off [benefits], or can sanction you".

Participants held views about who used foodbanks prior to using them. Fay had seen a television programme about foodbanks and said "... that's so sad because people appear with kids and then they're going to the foodbank with buggies", but she viewed them as places to help people and was impressed with the array of foods they received. A few participants felt that foodbanks were used or abused by people who did not really need to

\footnotetext{
${ }^{6}$ The Department for Work and Pensions is a UK government department responsible for welfare and pension policy.

${ }^{7}$ Jobcentre Plus is the part of the Department for Work and Pensions which delivers working-age support service in the UK.
} 
use them. Amanda suggested that there was stigma about foodbanks "because they are abused by the wrang kinda people, people that don't need them... like they'll spend their money on their selves, and then live aff foodbanks." Stacey said she did not want to go because she felt it would be "the people that stand about the shopping centre...your drug addicts and... alcoholics" adding that she was "lowering myself tae actually dae it, but I really needed it at the time". Thus, foodbank users engage in 'othering', internalising public discourse about the 'deserving' and 'undeserving' poor (Chase and Walker, 2013; Pemberton et al, 2016), and distancing themselves from unscrupulous, undesirable foodbank views.

And yet, foodbank users frequently had complex issues and difficult lives including multiple physical and mental health issues, dealing with unexpected bereavements, family crises, and living in hostile communities. Problems that might have been coped with in isolation can become insurmountable when they arrive on the back of others (Shildrick et al, 2016). Despite this, and partly due to public discourse, foodbank users can feel degraded despite their genuine needs. John was made redundant after 25 years of employment, he then became ill with a neurological condition and his health deteriorated so he was unable to work. Having provided for his family all his life, using a foodbank made him feel "degraded and just...horrible". Sue said she "never expected to be in that situation" of using a foodbank. Her life was turned upside down over a relatively short period of time through marriage breakdown, homelessness, having an accident at work and losing her job, and developing alcohol problems and mental health issues. She had no income for six weeks when she needed to use a foodbank.

Compared with other forms of help and welfare, foodbanks appear to have much deeper effects on people's sense of self and worthiness. Foodbank users have reported feelings of shame, stigma, fear and being blamed (van der Horst et al., 2014; Purdam, 2015) which can lead to people detaching themselves from society and from potential sources of help (Chase and Walker, 2013; Lister, 2015). For some participants, foodbank need and use indicated a failure, or demonstrated a deficit in a person's character or ability to cope. Foodbank use came as a shock to Jill who had a job and who never imagined herself to be in the same situation as other people who were struggling. She said "it's not one of these things that you would ever think that you would have to use", adding "I think it really badly affected me at the time psychologically and emotionally". Her foodbank use had a negative effect on wider family relationships. Others talked about feelings of shame in not being able to meet their 
family's "basic needs" (Debbie) or feed their children: "it makes me feel bad ... because I cannae afford tae feed my wean" (Susan). Matthew felt ashamed at "having nothing and having to go and get food from someone... because I was quite proud of being self-reliant."

\section{Referral and Access}

Foodbank users have on occasion to go to significant lengths to access them, including referral procedures and physically accessing projects in specific places and at specific times (Dowler and Lambie-Mumford, 2015). Getting a referral was not necessarily straightforward, and some participants said there were no notices or information available telling them where to find out about foodbank availability. John said "I can't see anybody just doing it for the sake of doing it". Debbie described her experience of waiting seven hours in a money advice centre in order to get a referral: "You've got tae go at six o'clock in the morning...It doesnae open tae half eight but you have to be there at six in the morning".

There were other practical issues in accessing foodbanks including getting there, carrying heavy bags home and difficulties for those with health and mobility issues or children to accompany. Fay and her family had a half hour walk each way. Fay was pregnant at the time and felt breathless, so the journey and carrying the shopping home was difficult. Kate chose not to return to the foodbank because it was difficult getting there: "I felt as if I had to keep asking somebody for a lift, and her having the wean, I went, I can't put her in that situation. I could have jumped a bus, but it's like, defeating the purpose". The foodbank Aisha used was a distance away from her house but the volunteers gave her money for a taxi home.

Several participants opted to use a foodbank further away from their home so that they could be more anonymous, including Jill who lived across the road from her nearest foodbank but chose to use one a bus journey away as "no one knew you there...I wasn't quite ready to let anyone know that we had to use a foodbank." Once in the foodbank, some hoped that no one they knew would see them there as Sue said "I hope nobody knows why I'm going in here, and I hope I don't meet anyone in here that I know". The nature and identification of food bank provisions also caused feelings of shame. Despite being a regular user of foodbanks, Stacey said that her son's friends could tell their food had come from a food bank because dates were written on the tins in a marker pen so were identifiable, and this made her feel "downgraded". 
Being a marker of poverty, the location and presentation of foodbanks can feed into users' feelings of shame and stigma (Pemberton et al, 2016; Chase and Walker, 2013; Reutter et al, 2009). The visible nature of some foodbanks displaying a 'foodbank' banner was an issue for some participants. Amanda said "it was a big sign, so it was kinda like marking you walking in, people knew what you were going in for". Fay hated using the nearest foodbank which had a banner outside, and even told her son to wait in the school for them for fear he might be bullied if his friends knew his family used a foodbank:

People see you coming out of there now, they start to look at you as if you were less than a dog (Fay)

\section{Experience: Supplies and Support}

\section{Food and other Provisions}

Most foodbanks provide basic rations. According to the Trussell Trust, a food parcel from one of its food banks provides a minimum of three days' worth of "nutritionally balanced, non-perishable" tinned and dried foods. Foodbanks varied in the extent to which they offered fresh food to users, which depended mostly on their relations with local supermarkets and whether they were independent or not, but most participants reported getting a lot of tinned and dried goods such as pasta, rice, tinned soup, breakfast cereal, long-life milk, tea and coffee meaning that people had basic rations and would not need to go hungry. Small, sweet treats beyond the basics were, however, much appreciated by users. This differs to what is available through community food projects that are more likely to offer healthier produce.

Many foodbanks had expanded their provision beyond basic foodstuffs, although food remains their main supply. Foodbank users with very limited incomes also appreciated the battered tins or items past their sell-by dates which they could help themselves to, as well as 'treats' such as jam, tinned fruit, biscuits, hot dogs and children's selection boxes at Christmas. Sue was appreciative of the toiletries she got: "And what I thought was really 
quite special in one of the bags was a toilet roll, a bar of soap, and a bottle of shampoo". There was particular gratitude for the supply of toiletries and sanitary products:

"The good thing [about the] the foodbank is, I was running low on toiletries and on woman stuff, and I said to them, and they gave me a nice bag of, you know, feminine stuff. It was great ... It was brilliant." (Alex R13)

In some cases, foodbanks paid particular attention to the needs of children and mothers. Stacey's daughter's child was called the 'foodbank baby' as she got supplies of nappies, wipes and fortified breastfeeding biscuits from the foodbank. For many other people, the fact that the foodbank would give them pet food for their dogs and cats mattered a lot.

\section{Beyond Food}

This non-food related support given by foodbanks - a listening ear, signposting, a hot drink and space to chat - was a key finding welcomed by participants, in line with other research (Garthwaite et al, 2015). It is common for foodbank users to have experienced chronic poor health conditions, mental health issues in particular, bereavement, relationship problems, substantial caring responsibilities or job loss (Garthwaite, 2016). We found that participants had high support needs and, whilst most participants were in receipt of support from a range of agencies, some lacked the right type or frequency of support, particularly in dealing with issues associated with loneliness, anxiety, and other mental health issues. Foodbanks played a therapeutic role for some people dealing with such issues. For some participants, knowing that there was someone in the foodbank they could talk to either about their situation, or just when they were feeling down, was a comfort. Amanda said that "if l'd had naebody to talk to, they would o' listened", and Maggie said "you can go o'er and speak to them if you feel depressed". Stuart commented that when he was feeling down the volunteers said "we're here if you need a wee chat".

Many participants were surprised at how welcoming the foodbank was, in terms of the overall set-up and the calm and supportive atmosphere. The foodbanks participants described were mainly café-style in that upon arrival people were greeted and offered food and drink by volunteers. Debbie said that the church minister welcomed her "wi' open arms so he made me feel at ease" and she was surprised to get a cup of tea from someone she 
didn't know. There was a general sense that users felt less isolated at foodbanks and valued meeting other people in a similar position to themselves. Many foodbank users had become known by name to the volunteers who often tried to help them in other ways such as providing information on other services, as well as being someone to talk to. This welcoming approach compared positively with some foodbank users' experiences in their local benefits offices where they had witnessed arguments and shouting (Purdam, 2015).

An important element of participants' foodbank experience was the values exhibited by volunteers. Susan said the volunteers were "very, very respectful. They don't look down on you. ...they make you feel welcome all the way." Amanda said the people at the food bank "had total respect... like it was like they understand mair... they didnae judge you". Matthew emphasised the compassion of the volunteers and how they eased some of the shame and stigma people felt about using a foodbank:

Compassionate... They actually want to listen... They don't judge you 'cause of your circumstances...They just treat you like a human (Matthew)

Jill said the volunteers were "aware of everyone's situations". She was very emotional during her first visit but said the volunteers easily coped with this and treated her with kindness:

They get it a little bit more, so they were a little bit more understanding and they didn't actually panic when I kind o' burst out crying the first time I went in...they weren't phased by that at all (Jill)

In other cases, the foodbank volunteers were a source of social contact as many users had few family or friends to talk to or rely on. Several participants said there was little or nothing available locally to meet their social needs, or that they lacked awareness about things going on due to their own withdrawal. Many expressed the desire just for a place to go and get out of the house or to meet up for a chat. Bobby was a frequent foodbank user as the local community café had closed down and there was nowhere to go "except meet up in Greggs [the bakery]." About going to the foodbank he said "It's more for company now... I have a gab, have your tea, coffee, biscuits.... It gets you oot o' the four walls". 
Foodbanks had also helped a few participants gain new volunteering opportunities that either helped them move towards employment or overcome isolation. Stuart had found out about voluntary work on a community food project for older people. Zina, a former asylum seeker, had found out about different projects through the foodbank: she was a lone parent to her six-year-old daughter and was undergoing the asylum process alone.

We were in asylum, we're not allowed to work, we're not allowed to do anything. But when you get to [foodbank], they ... interact with you and tell you you can volunteer, you can do this, you can do that. So they told me organisations I could go to, [that] have something for me, I could learn new things and stuff (Zina)

\section{Bad and Good}

The foodbank experience produced a range of responses in users that countered their public vilification. The charitable nature of foodbanks caused people to question their own entitlement. Many felt others were worse off than they were so should be given priority even though everyone was entitled. The experience of using a foodbank opened some people's eyes to the problems that many of their fellow citizens were encountering such as levels of poverty, sadness, and unfairness in society, and wanted to do something about this. Some participants came to realise that others were experiencing similar problems to themselves, whilst others became less judgemental and more empathetic as a result. Some questioned the notion of foodbanks in a rich country, yet appreciated their existence:

I find for a country like this, for people to resort to the foodbank is not nice. But thank God it is there for people who really can't get any better (Edwin)

A few participants never fully got over their feelings of shame or stigma associated with foodbank use and hoped never to have to use them again. Amanda said "I think l'd still be quite embarrassed if I had tae go back, because o' the way it is." And Debbie said "I just pray and hope I don't need tae go through it again". 


\section{Conclusion}

This paper has examined the nature of the relationship between foodbanks and the state, identifying three key paradoxes. We identified an unusual, yet interesting, voluntary sector relationship with the state which is about more than financial cutbacks and the voluntary sector response. The recent debate around foodbanks has mainly focused on their provision of basic needs and sustenance, and responding to emergency crises. However, if the debate is widened then a light is shone on the proper role of the state and its function in society. The role of the voluntary sector and its relationship with the state is not only about what the state provides (or does not), but about how the state operates as a provider. The state relationship with citizens is a crucial part of citizens' lives and sense of self. With regard to welfare reform - conditionality, regulation of people's job seeking behaviour - people's sense of self as citizens with rights is eroded, and social and emotional support removed. This has heightened citizens' experience of voluntary sector provision, which in the case of foodbanks has given citizens' dignity, respect and emotional and practical support that has been lacking from, or indeed eroded by, the state, in addition helping to tackle loneliness and low self-esteem. Thus, the relationship between the state and voluntary sector, and their meaning to citizens, has become as much about the how of provision as the what; this is not how the inter-sectoral relationship is usually discussed. The debate about foodbanks is kept narrow, we would argue, so as to avoid highlighting this question about the proper role the state as a signifier of the status and worth of citizens.

Recent research has shown how cutbacks in the welfare state, through widening conditionality and narrowing entitlements, has 'driven the need for foodbanks' as people's incomes have been reduced or removed (Lambie-Mumford 2018). In response, foodbanks have engaged in organisational growth, the reorganisation and professionalization of their supply processes, and the formation of partnerships with food suppliers and retailers. In this sense, foodbanks have acted in accord with the communitarian thrust of recent governments, taking up the slack and demonstrating voluntary and community sector responsibility for the welfare of fellow citizens (Fyfe 2005; Lambie-Mumford 2018). The state has also come to rely upon the contribution of foodbanks whilst denying this is the case for fear of the shame of admitting the presence of destitution in the UK and of relying on voluntary efforts which have not been officially solicited. Foodbanks meanwhile are keen to refute that they have a role within the welfare state. Witness the contradictory remarks made by the Trussell Trust that 'we have to be there because the statutory safety net has too many holes in it' but that it will never become 'a pseudo-safety net that lets the state off the hook' 
(Butler 2018, p.34). These circumstances represent not a state-voluntary sector compact so much as a contradiction.

In our research of foodbank users, we have shown that reforms to the welfare state have done more than cause the growth of foodbanks. Many people have been badly affected financially, psychologically and emotionally by reductions in welfare spending, reductions to incomes, but also through measures such as increased sanctioning and appeals, and the impact of these processes. How the welfare state behaves, its objectives and processes, has impacts both on foodbanks - in terms of what they provide and how they provide it, and on foodbank users - in terms of how they experience foodbanks. We observed a paradox in access routes to foodbanks: some people are referred by state welfare agencies who recognise needs that the state is unable or unwilling to meet, partly due to austerity. Thus, foodbanks have become an established, informal part of the welfare system. This is a manifestation of the paradox that people are referred to foodbanks by welfare agencies, to deal with the consequences of welfare reforms.

It was also the charitable nature of foodbanks, and their reputation from the media, that created feelings of shame and stigma for many. Shame and stigma affected how and where people accessed foodbanks and stored foodbank provisions in order to avoid negative judgements of friends or acquaintances. Foodbank users internalised the negative discourse about users and engaged in 'othering', but the experience of foodbanks made them more empathetic and less judgemental in time. The charitable nature of foodbanks caused users to feel less entitled than others to such help, but also motivated them to want to make a contribution to foodbanks once their own circumstances had stabilised.

Thus, there was a paradox in that participants' experience of foodbanks was very different from their expectations. Encounters with state officials, when dealing with the welfare system, were described as being distrustful, disrespectful, unpleasant and sometimes threatening, and this had consequences for participants' expectations of foodbanks. Their experience, however, was contrary to this. The respectful, dignified and supportive interactions that users had with volunteers was amongst the most valued aspects of foodbanks, i.e. foodbanks were about more than food. The welfare state in terms of its recent reforms is experienced as punitive, but voluntary foodbanks as kind but charitable. Although the welfare state was formed on social entitlement not charity, the latter is 
appreciated more than the former in current circumstances. What seems important is that foodbanks as part of the voluntary sector play an important role in welfare provision not because they are professionalised, but because they are humanised, i.e. values matter more than business acumen (McCabe, 2012).

Welfare reform has led to reductions in incomes and cutbacks in essential services for those on low incomes and/or with complex needs. While many participants were in receipt of support from a range of agencies, they still felt they were not getting the right level or appropriate support. For some people foodbanks filled a gap in terms of social contact, provided therapeutic support (a listening ear), and directions to new social and volunteering opportunities, which are important for improved quality of life. This is not surprising as poverty is isolating, and social withdrawal a downward spiral for those with additional mental health issues and absence of family ties. Foodbanks are the way they are because they are charities run by volunteers, and yet a truly equitable society would not require charity to help people who have been failed by the state in meeting their basic needs. Thus, foodbanks are providing the support that arguably should be provided by other state or voluntary organisations in a more co-ordinated manner.

Our third paradox concerned community food initiatives where the emphasis is on empowerment and mutual aid rather than charity. No one in our study had any involvement with such projects or knew of their existence. The Scottish Government's Fair Food Transformation Fund has provided funding to foodbanks in order to modify their current approach to emphasise the "dignity" of service users (Scottish Government, 2018). This is an example of integrating emergency food provision into a wider range of community-based activities in order to move from charitable provision to a food justice model. Although CFIs currently tend to run in parallel with the more traditional foodbank set-up as the dominant model, alternative forms of food aid could play a role for some of the people currently needing to use foodbanks. But it is not a panacea due to the high levels of people affected by financial hardship, and the multiple and sometimes intractable problems they are encountering alongside this.

There are fundamental repercussions arising from the paradoxical growth of foodbanks in a modern welfare state. The normalisation of foodbanks as an everyday response to austerity can mean there is little motivation for policymakers to seek alternatives. Thus the social 
right to be 'free of want' (Beveridge, 1942) may be eroded by austerity-justified welfare reform (Schrecker and Bambra, 2017), backed up by foodbank provision. Indeed, charity in the form of foodbanks is highly depoliticizing: it allows the state to evade its obligations while still maintaining a degree of control, and allows the public to consider that 'something is being done' rather than seeking to address the issue of food insecurity (Caplan, 2016).

The preferred solution is to have a more compassionate welfare state, based on entitlement and fairness and which meets people's needs with dignity and respect, in addition to tackling the underlying causes and consequences of poverty and hardship. And there are lessons to be learned from foodbanks in this: about their set-up, treatment and care towards vulnerable people, and as places for support and social contact. Indeed, in Scotland, the establishment of an independent Social Security Agency provides an opportunity to acquire and use this learning in developing a new 'person-centred' service (Scottish Government 2017). There is also growing recognition of the importance of human connection and relationships for individual and societal wellbeing in public policy (Unwin, 2018). Thus, there is the prospect that the state (re)learns how to provide from the example of foodbanks. 
Table 1. Summary of sample characteristics.

\begin{tabular}{|c|c|}
\hline Gender & 14 female, 9 male \\
\hline Age range & $21-65$ \\
\hline $\begin{array}{l}\text { Household } \\
\text { composition }\end{array}$ & $\begin{array}{l}10 \text { family households (i.e. at least } 1 \text { adult } \& 1 \text { child/young person } \\
<18 y r s \text { ) } \\
11 \text { single occupancy } \\
1 \text { couple }\end{array}$ \\
\hline Ethnic background & $\begin{array}{l}19 \text { white, } 4 \text { BAME (3 former asylum seekers now with 'leave to } \\
\text { remain' status) }\end{array}$ \\
\hline Work status & $\begin{array}{l}\text { At the time of food bank use, } 2 \text { participants were in part-time } \\
\text { work. All others were in receipt of state benefits. }\end{array}$ \\
\hline
\end{tabular}




\section{References}

Adler,M (2016). A New Leviathan: Benefit Sanctions in the Twenty-first Century. Journal of Law and Society, 43,2,195-227

Alcock,P. (2010). Partnership and mainstreaming: voluntary action under New Labour. Third Sector Research Centre Working Paper 32. Birmingham: Birmingham University.

Beveridge,WH (1942). Social Insurance and Allied Services: Beveridge Report. HM Stationery Office, London

Caplan,P. (2016) 'Big society or broken society?: Food banks in the UK', Anthropology Today, 32,1,5-9.

Caraher, M. and Dowler, E. (2014). Food for Poorer People: Conventional and "Alternative" Transgressions. In: Goodman, M. and Sage, C. (Eds.), Food Transgressions:Making Sense of Contemporary Food Politics. (pp. 227-246). Farnham, Surrey: Ashgate.

Chase,E, Walker,R, 2013, The co-construction of shame in the context of poverty: Beyond a threat to the social bond, Sociology 47,739-54

Deakin,N. (1996) Commission on the Future of the Voluntary Sector. Meeting the Challenge of Change: Voluntary Action in the 21st Century. London: NCVO.

Department for Work and Pensions (2013). Jobseekers Allowance: overview of revised sanctions regime. London: DWP

Dowler,E and Caraher,M (2003). Local Food Projects: The New Philanthropy. The Political Quarterly, 74,1, 57-65

Dowler,E. and Lambie-Mumford,H. (2015) 'How can households eat in austerity? Challenges for social policy in the UK', Social Policy and Society 14,3,417-428.

Dowler,E and O'Connor, D (2012). Rights based approaches to addressing food poverty in Ireland and the UK. Social Science and Medicine, 74,1,44-51

Edmiston,D (2017) 'How the other half live': Poor and Rich Citizenship in Austere Welfare Regimes. Social Policy and Society, 16,2,315-325

Egan, M. et al. (2010) Protocol for a mixed methods study investigating the impact of investment in housing, regeneration and neighbourhood renewal on the health and wellbeing of residents: the GoWell programme. BMC Medical Research Methodology, 10,1,41

Equality and Human Rights Commission (2018). The impact of welfare reform and welfareto-work programmes: an evidence review

Fletcher,D and Wright,S (2018). A hand up or a slap down? Criminalising benefit claimants in Britain via strategies of surveillance, sanctions and deterrence. Critical Social Policy, 38, 2, 323-344 
Fyfe, N (2005). Making Space for "Neo-communitarianism"? The Third Sector, State and Civil Society in the UK, Antipode, 37,3,536-557

Garthwaite,K (2011). The language of shirkers and scroungers? Talking about illness, disability and Coalition welfare reform. Disability and Society, 26,3,369-72

Garthwaite,K., Collins,P.J. and Bambra,C. (2015) 'Food for thought: an ethnographic study of negotiating ill health and food insecurity in a UK foodbank', Social Science and Medicine, $132,38-44$.

Garthwaite,K. (2016) Hunger Pains: Life Inside Foodbank Britain, Bristol:Policy Press

Garthwaite,K (2016). Stigma, shame and people like us: an ethnographic study of foodbank use in the UK, Journal of Poverty and Social Justice, 24, 3, 277-89

GoWell (2016). GoWell Briefing Paper 28. Food bank use among residents of Glasgow's deprived neighbourhoods. GoWell: Glasgow

Home Office (1998). Compact on Relations Between Government and the Voluntary and Community Sector in England. London: Stationery Office.

Home Office (1990). Efficiency Scrutiny of Government Funding of the Voluntary Sector: Profiting from Partnership. London: Home Office.

Hood, A and Waters, T (2017). Living standards, poverty and inequality in the UK: 2017-18 to 2021-22. The Institute for Fiscal Studies, London

House of Commons Work and Pensions Committee (2018). PIP and ESA assessments: claimants experiences

https://publications.parliament.uk/pa/cm201719/cmselect/cmworpen/355/355.pdf

lafrati,S. (2018). "We're not a bottomless pit": food banks' capacity to sustainably meet increasing demand. Voluntary Sector Review, 9:1,39-53

Lambie-Mumford, $\mathrm{H}$ (2018). The growth of food banks in Britain and what they mean for social policy, Critical Social Policy.

Lambie-Mumford,H (2017). Hungry Britain: the rise of food charity, Bristol: Policy Press

Lewis,J. (1999) 'Reviewing the relationship between the voluntary sector and the state in Britain in the 1990s', Voluntas, 10:3, 255-270.

Lister,R. (2015) “'To count for nothing”: poverty beyond the statistics', Journal of the British Academy, 3,139-65

Loopstra,R., Fledderjohann,J., Reeves,A and Stuckler,D (2018). Impact of welfare benefit sanctioning on food insecurity: a dynamic cross-area study of food bank usage in the UK.

Mattheys,K. Warren,J \& Bambra,C (2017). "Treading in sand": A qualitative study of the impact of austerity on inequalities in mental health. Social Policy and Administration 
McCabe,A. (2012). Is the third sector so special? What is it worth? London: Third Sector Research Centre.

McNeil,C., Hochlaf,D and Quilter-Pinner,H (2019). Social (in)security: Reforming the UK's social safety net. Institute for Public Policy Research

Patrick,R, (2014). Working on welfare: Findings from a qualitative longitudinal study into the lived experiences of welfare reform in the UK, Journal of Social Policy 43, 705-25

Pemberton,S, Fahmy,E, Sutton,E, Bell,K (2016). Navigating the stigmatised identities of poverty in austere times: Resisting and responding to narratives of personal failure, Critical Social Policy 36, 21-37

Perry, $\mathrm{J}$ et al (2014). Emergency use only: understanding and reducing the use of food banks in the UK, Oxfam

Purdam,K (2015). Hungry? Food Insecurity, Social Stigma and Embarrassment in the UK, Sociology

Rethink Mental IIIness (2017). 'It's broken her: assessments for disability benefits and mental health. www.rethink.org

Reutter,LI., Stewart,MJ., Veenstra,G., Love,R et al (2009). Who do they think we are, anyway?: perceptions of and responses to poverty stigma. Qualitative Health Research, 19, $3,297-311$

Saxena,LP and Tornaghi,C (2018). The Emergence of Social Supermarkets in Britain: Food poverty, Food waste and Austerity Retail, CAWR Coventry University

Schrecker,T and Bambra,C (2015). How politics makes us sick. Palgrave Macmillan

Scottish Council for Voluntary Organisations (SCVO) (2014). Third sector and welfare on the frontline

Scottish Government (2017). Social Security Agency Implementation. Edinburgh: Scottish Government

ShildrickT, MacDonald,R, Furlong,A (2016). Not single spies but in battalions: a critical, sociological engagement with the idea of so-called 'Troubled Families'. The Sociological Review 64, 4, 821-836

Trussell Trust (2016, 2017, 2019) Latest Stats https://www.trusselltrust.org/news-andblog/latest-stats/end-year-stats/https://www.trusselltrust.org/2016/04/15/food bank-useremains-record-high/

Unwin, J (2018). Kindness, emotions and human relationships: the blind spot in public policy. Carnegie UK

van der Horst,H., Pascucci,S Bol ,W (2014). "The "dark side" of food banks? Exploring emotional responses of food bank receivers in the Netherlands", British Food Journal, 116, $9,1506-1520$ 
Warren,J., Garthwaite,K, and Bambra,C (2014). After Atos Healthcare: Is the Employment and Support Allowance fit for purpose and does the Work Capability Assessment have a future? Disability and Society, 29,8,1319-1323

Webster,D. (2014). Independent review of Jobseeker's Allowance (JSA) sanctions for claimants failing to take part in back-to-work schemes.

Wells,R. and Caraher,M. (2014). 'UK print media coverage of the food bank phenomenon: from food welfare to food charity?', British Food Journal, 116, 9, 1426-45.

White, $G$ (2014). The impact of welfare reform on the third sector care and support services in Scotland. IRISS/CCPS

Wright,S (2012). Welfare-to-work, agency and personal responsibility. Journal of Social Policy, 41,2,309-28.

Wright,S. (2016) Conceptualising the active welfare subject: welfare reform in discourse, policy and lived experience. Policy and Politics, 44,2, 235-252. 